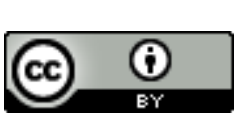

\title{
ALUNOS COM SÍNDROME DE ASPERGER: \\ O INTÉRPRETE DE ENUNCIADOS E O ACESSO À EDUCAÇÃO SUPERIOR
}

\author{
STUDENTS WITH ASPERGER SYNDROME:
}

THE INTERPRETER OF STATEMENTS AND ACCESS TO HIGHER EDUCATION

\section{ALUMNOS CON SÍNDROME DE ASPERGER: \\ EL INTÉRPRETE DE ENUNCIADOS Y EL ACCESO A LA EDUCACIÓN SUPERIOR}

Silvia Ester Orrú1

\begin{abstract}
RESUMO: O artigo tem como objetivo retratar as demandas das pessoas com Síndrome de Asperger para o acesso e conclusão dos cursos de ensino superior no Brasil, bem como dos processos seletivos vestibulares a partir da legislação e políticas pró-inclusão. O plano metodológico diz respeito a análise documental e bibliográfica com abordagem qualitativa. $\mathrm{O}$ intérprete de enunciados é descrito como recurso favorecedor ao acesso na educação superior. As conclusões apontam que os processos seletivos vestibulares rompem com a lógica da legislação vigente que orienta à realização de alterações que favoreçam a pessoa com deficiência ao alcance dos níveis mais elevados de ensino.
\end{abstract}

PALAVRAS-ChAVE: Síndrome de Asperger. Inclusão. Vestibular. Intérprete de enunciados.

ABSTRACT: The article aims to portray the demands of people with Asperger's Syndrome for access and completion of higher education courses in Brazil, as well as selective exams processes based on legislation and pro-inclusion policies. The methodological plan concerns documentary and bibliographic analysis with a qualitative approach. The interpreter of statements is described as a facilitator of access in higher education. The conclusions suggest that the vestibular selective processes break with the logic of legislation that guides the implementation of changes that favor the person with disabilities to reach higher levels of education.

KEYWORDS: Asperger's Syndrome. Inclusion. Entrance exam. Interpreter of statements.

RESUMEN: El artículo tiene como objetivo retratar las demandas de las personas con Síndrome de Asperger para el acceso y conclusión de los cursos de enseñanza superior en Brasil, así como de los procesos selectivos vestibulares a partir de la legislación y políticas pro-inclusión. El plan metodológico se refiere al análisis documental y bibliográfico con abordaje cualitativo. El intérprete de enunciados se describe como un recurso favorable al acceso a la educación superior. Las conclusiones apuntan que los procesos selectivos vestibulares rompen con lógica de la legislación vigente que orienta a la realización de alteraciones que favorezcan a la persona con discapacidad al alcance de los niveles más elevados de enseñanza.

PALABRAS ClAVE: Síndrome de Asperger. Inclusión. Examen de entrada. Intérprete de enunciados.

Submetido em: 05/06/2018 - Aceito em: 07/07/2018 - Publicado em: 18/01/2019

\begin{tabular}{l|c|c|c|c|c|c} 
(C) Rev. Educ. Perspec. & Viçosa, $M G$ & v.9 & n.3 & p.668-693 & set./dez. 2018 & eISSN 2178-8359 \\
\hline
\end{tabular}




\section{INTRODUÇÃO}

A Síndrome de Asperger (SA) até 2012, integrava-se à classificação dos Transtornos Invasivos do Desenvolvimento, representada por danos graves e agressivos em várias áreas do desenvolvimento, com prejuízo nas habilidades da interação social recíproca, de comunicação, na presença de comportamentos, nos interesses e atividades estereotipadas. Segundo o DSM-IVi:

\footnotetext{
Os prejuízos qualitativos que definem essas condições representam um desvio acentuado em relação ao nível de desenvolvimento ou idade mental do indivíduo. Esta seção abarca Transtorno Autista, Transtorno de Rett, Transtorno Desintegrativo da Infância, Transtorno de Asperger e Transtorno Invasivo do Desenvolvimento sem outra especificação (APA, 1994).
}

Atualmente, após a publicação da quinta versão do DSM pela APA (2013), a SA deixou de constar como uma das categorias de classificação do autismo, sendo incorporada ao diagnóstico de Transtorno do Espectro Autista (TEA) que se define como um conjunto de manifestações com diferentes níveis de comprometimento com a presença de alterações na comunicação social e de comportamentos repetitivos e estereotipados. A SA é uma categoria presente nos Transtornos Globais do Desenvolvimento (TGD) (APA, 1994) e apresenta alteração qualitativa nas interações sociais recíprocas e um repertório de interesses e atividades restritos, fala e comportamentos estereotipados e repetitivos (OMS, 1993).

A SA apresenta desvantagens na interação social, interesses restritos e comportamentos circunscritos. Não são encontrados atrasos clinicamente relevantes na linguagem oral ou na percepção da linguagem, no desenvolvimento cognitivo, nas habilidades de autocuidado e na curiosidade sobre o ambiente (KLIN, 2006).

Enquanto que na décima edição da Classificação Internacional de Doenças e Problemas relacionados à Saúde (CID) também conhecida como Classificação Internacional de Doenças (OMS, 1993) e na quarta versão do DSM (APA, 1994), agrupava-se em TGD as categorias: Autismo infantil, Síndrome de Asperger, Transtorno Desintegrativo, Autismo Atípico, Síndrome de Rett, a quinta versão do DSM (APA, 2013), determinou haver somente uma categoria denominada de TEA. Portanto, a SA passa a pertencer a essa nova nomenclatura diagnóstica. Entretanto, permanecem os domínios referentes ao déficit de comunicação social e de comportamentos, interesses restritos e repetitivos.

O DSM-V (APA, 2013) classifica o TEA por níveis de comprometimento da seguinte forma: autismo leve (N1), autismo moderado (N2) e autismo grave ou severo (N3). De acordo com o nível de comprometimento manifestado, maiores são as necessidades de apoio para a pessoa com TEA. A SA, relaciona-se, portanto, às características do TEA na forma de autismo leve (N1), no qual apresenta a necessidade de algum suporte, mais relacionado às dificuldades no

\begin{tabular}{l|l|l|l|l|l|l} 
(C) Rev. Educ. Perspec. & Viçosa, $M G$ & v.9 & n.3 & p.668-693 & set./dez. 2018 & eISSN 2178-8359 \\
\hline
\end{tabular}


processo de comunicação, embora não sejam restringentes ao desenvolvimento da interação social. Similar, pessoas com SA, costumam necessitar de apoio para planejarem suas atividades e organizarem-se de forma a desenvolverem sua autonomia.

Segundo dados do Centers for Disease Control and Prevention (CDC, 2013), entre 2011 e 2012, o governo dos Estados Unidos divulgou que a cada 50 crianças entre 6 e 17 anos, havia 1 com autismo, portanto, uma incidência de 2,0\%. Em 2011 a prevalência com base em estimativas era de $1 \%$ na Finlândia e na Suécia e 1,5\% na Dinamarca. Lyall et al. (2017) ressalvam que toda a epidemiologia descritiva está relacionada às crianças, sendo que, apenas a Inglaterra, em 2007, realizou um estudo rigoroso acerca do autismo em adultos, com uma estimativa de 1\%. Em novembro de 2017, o CDC (2017) divulgou que, conforme informações do National Health Information Survey (NHIS), a taxa de autismo para 2016 era de $2,76 \%$, ou seja, 1 em cada 36 crianças americanas, um aumento de $147 \%$ de casos em menos de 10 anos.

No Brasil há poucos estudos epidemiológicos sobre a incidência do autismo, por isso não há dados estatísticos precisos. Todavia, em 2007, o Projeto Autismo, do Instituto de Psiquiatria do Hospital das Clínicas, da Escola Paulista de Medicina (Unifesp), estimou haver cerca de 2 milhões de casos de autismo para uma população de 190 milhões de pessoas (MERCADANTE, 2010). Não há fontes precisas quanto à prevalência de SA no Brasil, a estimativa é de 3 casos para cada 10.000 nascimentos (AMORIM; ASSUMPÇÃO, 2012). Conforme os estudos de Klin (2006), há 1 indivíduo com SA para cada 200.

De acordo com a ONU (2017), 1 em cada 160 crianças apresenta o TEA, sendo a estimativa de $1 \%$ da população planetária, cerca de 70 milhões de pessoas, prevalência de 4 casos para o sexo masculino e 1 para o feminino. Estima-se que a cada 250 pessoas, 1 tenha SA, a forma mais branda do TEA (N1). Em razão da ausência de dados oficiais sobre a epidemiologia da SA, a Confederação Asperger Espanha (2017) calcula que há entre 1 e 5 casos a cada 1000 nascimentos.

Acerca das características comuns às pessoas com SA, de acordo com a literatura científica, as manifestações do quadro sintomático costumam ser reconhecidas após os 3 anos de idade e com a ocorrência do diagnóstico clínico por volta dos 5 ou 6 anos de idade e suspeita de superdotação (SCHWARTZMAN, 1992). A capacidade de percepção se mostra orientada ao todo e com associação à memória excepcional (ASPERGER, 1944; APA, 1994; RODRIGUES; ASSUMPÇÃO JR, 2011). Embora superficial, é possível perceber a existência de contato visual (ASPERGER, 1944; SCHWARTZMAN, 1992; KLIN, 2003). Quanto ao desenvolvimento social, este acontece de forma espontânea, porém, com memorização das regras relacionadas ao jogo social (SCHWARTZMAN, 1992; KLIN, 2003). Interesses específicos, restritos e não usuais são percebidos desde o início do

\begin{tabular}{l|l|l|l|l|l|l} 
(C) Rev. Educ. Perspec. & Viçosa, $M G$ & v.9 & n.3 & p.668-693 & set./dez. 2018 & eISSN 2178-8359 \\
\hline
\end{tabular}


desenvolvimento com exploração adequada dos objetos (ASPERGER, 1944; APA, 1994). Os interesses ou hiperfoco, costumam estar mais relacionados às áreas intelectuais bem específicas e restritas (SACKS, 1995; BAUER, 1996). No que diz respeito ao desenvolvimento da linguagem, é comum não haver atraso no aparecimento da fala, sendo esta, estruturada gramaticalmente. Porém, costuma ser pedante, incomum à idade e com alterações pragmáticas (PASTORELLO, 1996; MARTIN; MACDONALD, 2003). Sobre o desenvolvimento da leitura e da escrita, comumente se manifesta de modo espontâneo e em idade extemporânea na maioria dos casos (hiperlexia) (SCHWARTZMAN, 1992; LOPESHERRERA, 2005). Schwartzman (1992) também descreve que pessoas com SA costumam apresentar interesses específicos, o que pode dificultar seu processo de interação social. Conversas sobre astronomia, matemática, artes, idiomas, dentre outras que podem não ser do interesse da maioria dos colegas e demais pessoas. Sobre os assuntos que têm apreço, costumam ler com frequência e memorizar as informações relacionadas aos temas, deixando seus ouvintes surpresos com o conhecimento que possuem (ORRÚ, 2010; 2016).

Embora pela atual nomenclatura do DSM V (APA, 2013), a SA seja diagnosticada no âmbito do TEA, como sendo uma forma mais branda ou leve do autismo (Nível 1), optou-se, neste artigo, pela manutenção do termo SA para melhor especificação das singularidades que fazem parte da constituição subjetiva desta pessoa. Inclusive, considerando que os jovens que atualmente pleiteiam e adentram ao ensino superior, receberam esse diagnóstico que se manteve até o ano de 2013. Ou seja, os laudos em mãos dos candidatos no tempo presente, ainda se referem ao diagnóstico realizado a partir do DSM-IV e são esses que chegam às universidades para a solicitação de recursos às demandas singulares dos mesmos. Não obstante, a SA permanece como uma das categorias de preenchimento do Censo da Educação Superior, como se pode constatar desde o período de 2011 a 2016 (BRASIL, 2013; 2017a). Espera-se que com o conhecimento e a ampla vigência do DSM-V, a nova nomenclatura e terminologia disposta como TEA, absorva a SA para o melhor entendimento da complexidade do autismo.

\section{MÉTODO}

$\mathrm{O}$ estudo trata de pesquisa com abordagem qualitativa e tem como objetivo retratar as demandas das pessoas com Síndrome de Asperger para o acesso e conclusão dos cursos de ensino superior no Brasil, bem como dos processos seletivos vestibulares a partir da legislação e políticas pró-inclusão. Para tanto, faz-se uso de análise documental e bibliográfica.

No que diz respeito à pesquisa documental, segundo Gil (2002), essa é restrita à utilização de documentos escritos ou não, constituindo o que se denomina de fontes primárias. Neste

\begin{tabular}{l|c|c|c|c|c|c} 
(c) Rev. Educ. Perspec. & Viçosa, $M G$ & v.9 & n.3 & p.668-693 & set./dez. 2018 & eISSN 2178-8359 \\
\hline
\end{tabular}


prisma, como base para o desenvolvimento do estudo proposto, enfatizou-se a Convenção sobre os Direitos das Pessoas com Deficiência (ONU, 2006) e o Decreto 7.611/2011 (BRASIL, 2011a). Ambos os documentos favorecem o entendimento sobre a discussão proposta.

A pesquisa bibliográfica foi empreendida para a discussão e explicação do tema proposto. Foram utilizados artigos, livros, teses, documentos como fontes secundárias e outras publicações compreendidas como fontes relevantes de informações, esclarecimentos e contribuições para este estudo. Para a pesquisa de artigos foi utilizada a biblioteca eletrônica SciELO e o buscador Google Acadêmico. O critério de inclusão do material bibliográfico diz respeito à interlocução entre características próprias da SA e aspectos educacionais, bem como aqueles relacionados ao direito e acesso à educação superior no Brasil. O processo de investigação bibliográfica possibilitou a aproximação junto à literatura nacional e internacional sobre o tema. Foram selecionados e estudados os seguintes materiais:

a) Fontes nacionais: 09 documentos nacionais publicados pela República Federativa do Brasil, 09 publicações do Ministério da Educação (MEC) e do Instituto Nacional de Estudos e Pesquisas Educacionais Anísio Teixeira (INEP), 10 artigos científicos, 07 livros publicados no Brasil, 02 teses de doutorado e 06 publicações complementares que não se enquadram nas categorias anteriores.

b) Fontes internacionais: 08 documentos nos quais se enquadram publicações da Associação Americana de Psicologia (APA), Organização das Nações Unidas (ONU), Organização Mundial da Saúde (OMS), Education at a Glance (EAG), Centers for Disease Control and Prevention (CDC), 05 artigos científicos, 01 livro e 06 publicações complementares que não se enquadram nas categorias anteriores.

Não se teve como objetivo a delimitação de um período específico de produção científica sobre o assunto. Entretanto, enfatiza-se que a maior parte do material selecionado foi produzido entre 1994 a 2013, o que se justifica pela época de maior concentração de estudos e pesquisas sobre SA. Sobre os aspectos relacionados à educação na perspectiva inclusiva, a bibliografia central é de 2004 a 2017.

\section{OS PROCESSOS SELETIVOS VESTIBULARES E O INTÉRPRETE DE ENUNCIADOS COMO FAVORECEDOR DO ACESSO À EDUCAÇÃO SUPERIOR}

Com o aumento significativo de matrículas na educação básica, a partir das políticas públicas de inclusão, o número de matrículas na educação superior, também tende a crescer. Segundo

\begin{tabular}{l|c|c|c|c|c|c|} 
(C) Rev. Educ. Perspec. & Viçosa, $M G$ & v.9 & n.3 & p.668-693 & set./dez. 2018 & eISSN 2178-8359 \\
\hline
\end{tabular}


os dados do Censo Escolar da Educação Básica 2017 (BRASIL, 2018), o número de matrículas de alunos com deficiência foi de 827.243, com um salto de 85,5\% em 2013 para 90,9\% em 2017. Nesse conjunto de pessoas, incluem-se aquelas com TEA. Em 2015, no Ensino Médio, foram registradas 7,3\% de matrículas de alunos com Autismo infantil, Síndrome de Asperger e Transtorno Desintegrativo da Infância (INSTITUTO UNIBANCO, 2016), categorias integrantes do diagnóstico de TGD (APA, 1994). Como referência, vale dizer que, segundo dados da EAG (2017), no ano de 2015, adultos entre 25 e 64 anos, não tinham acesso ao Ensino Médio e cerca de $17 \%$ não tinham concluído a educação básica, sendo que somente $15 \%$ dos estudantes entre 25 e 34 anos cursavam o ensino superior.

Em 2011, pela primeira vez, foram incluídas as categorias de Autismo infantil, Síndrome de Asperger e Transtorno Desintegrativo da Infância no Censo da Educação Superior (BRASIL, 2013). Assim, com relação à permanência do aluno com TEA na educação básica e sua transição para o ensino superior, percebe-se que esta vem acontecendo de forma contínua, mesmo que de maneira discreta, pois segundo Goessler (2014) em 2011 havia 137 alunos e em 2012, 300 alunos matriculados no ensino superior nas categorias supracitadas. De acordo com o Censo da Educação Superior de 2015, 442 alunos com TEA estavam matriculados em cursos de graduação, já no Censo de 2016 (BRASIL, 2017a), constavam 591 estudantes com o diagnóstico em cursos de graduação no Brasil. Conforme o Gráfico 1, enquadram-se os números referentes às categorias integrantes do diagnóstico de TGD (APA, 1994). Este número diz respeito àqueles que se autodeclararam com os respectivos diagnósticos. Entretanto, supõe-se que o número de matriculados com TEA deva ser maior, visto que algumas pessoas preferem não informar o diagnóstico com receio de sofrerem estigmas e preconceitos ou mesmo, por desconhecerem que possuem essa singularidade, mesmo já estando na idade adulta (RÉVIL, 2012; CZELUSNIAK, 2013; KELTER, 2014; BBC, 2018). 


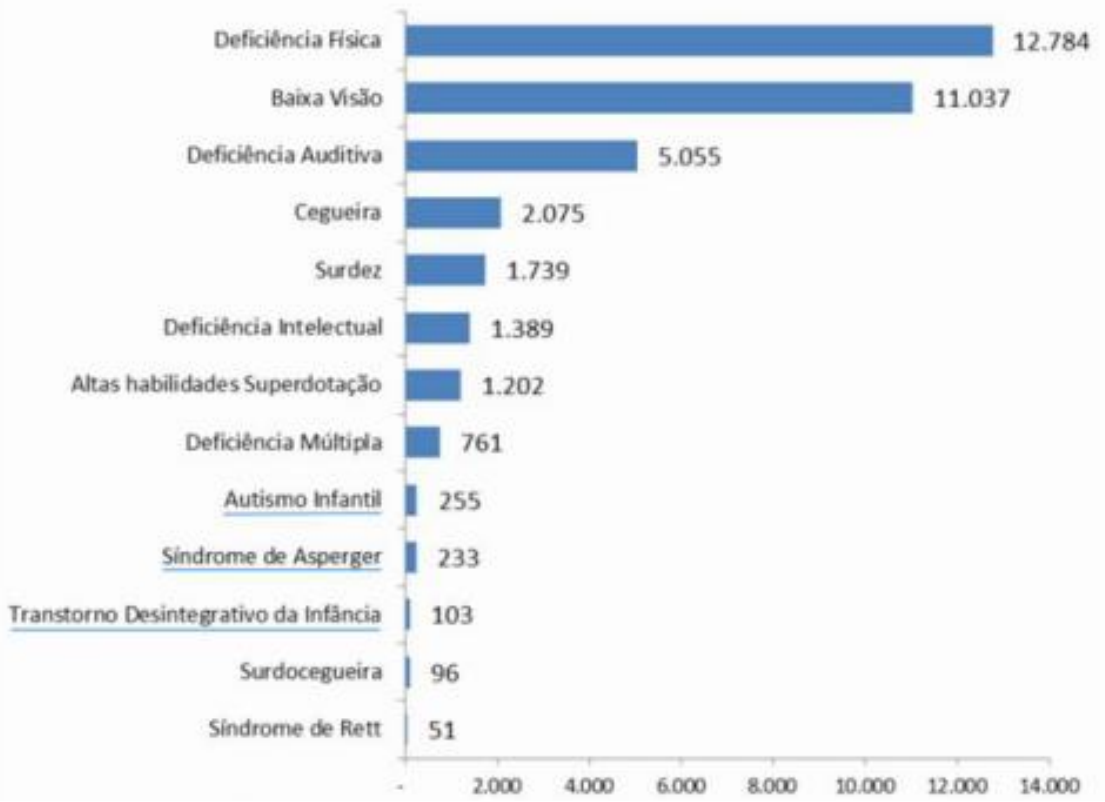

Gráfico 1. Matrícula na Educação Superior de alunos com deficiência, transtornos globais do desenvolvimento ou altas habilidades/superdotação - Brasil (2009-2016)

Fonte: Brasil, 2017a.

As políticas afirmativas para a educação brasileira possuem um acervo de leis e decretos, além de documentos orientadores de ordem nacional e internacional que versam sobre o direito de todos à educação (BRASIL, 2015b). Especificamente, com relação ao direito à educação superior da pessoa com deficiência, os princípios norteadores se encontram relacionados, em ordem cronológica, no quadro 1 :

Quadro 1. Documentos norteadores do direito à educação superior

\begin{tabular}{|c|c|c|}
\hline Documento & Princípio & Ano \\
\hline $\begin{array}{l}\text { Decreto } \mathrm{n}^{\circ} 5.296 \\
\text { (BRASIL, 2004) }\end{array}$ & $\begin{array}{l}\text { Regulamenta as Leis } \mathrm{n}^{\circ} 10.048 \text {, de } 8 \text { de novembro de } 2000 \text {, que dá } \\
\text { prioridade de atendimento às pessoas que especifica, e } \mathrm{n}^{\circ} 10.098 \text {, de } 19 \text { de } \\
\text { dezembro de } 2000 \text {, que estabelece normas gerais e critérios básicos para a } \\
\text { promoção de acessibilidade das pessoas portadoras de deficiência ou com } \\
\text { mobilidade reduzida, e dá outras providências. }\end{array}$ & 2004 \\
\hline $\begin{array}{l}\text { Decreto } \mathrm{n}^{\circ} 5.626 \\
\text { (BRASIL, 2005) }\end{array}$ & $\begin{array}{l}\text { Regulamenta a Lei } \mathrm{n}^{\circ} 10.436 \text {, de } 24 \text { de abril de } 2002 \text {, que dispõe sobre a } \\
\text { Língua Brasileira de Sinais - Libras, e o art. } 18 \text { da Lei }{ }^{\circ} 10.098 \text {, de } 19 \text { de } \\
\text { dezembro de } 2000 \text {. }\end{array}$ & 2005 \\
\hline $\begin{array}{l}\text { Organização das } \\
\text { Nações Unidas (ONU) }\end{array}$ & Convenção sobre os Direitos das Pessoas com Deficiência. & 2006 \\
\hline $\begin{array}{l}\text { Decreto Legislativo } \mathrm{n}^{\circ} \\
186 \text { (BRASIL, 2008a) }\end{array}$ & $\begin{array}{l}\text { Aprova o texto da Convenção sobre os Direitos das Pessoas com Deficiência } \\
\text { e de seu Protocolo Facultativo, assinados em Nova Iorque, em } 30 \text { de março } \\
\text { de } 2007 .\end{array}$ & 2008 \\
\hline $\begin{array}{l}\text { Decreto } \mathrm{n}^{\circ} 6.949 \\
\text { (BRASIL, 2009) }\end{array}$ & $\begin{array}{l}\text { Promulga a Convenção Internacional sobre os Direitos das Pessoas com } \\
\text { Deficiência e seu Protocolo Facultativo, assinados em Nova Iorque, em } 30 \\
\text { de março de } 2007 \text {. }\end{array}$ & 2009 \\
\hline $\begin{array}{l}\text { Decreto } \mathrm{n}^{\circ} 7611 \\
\text { (BRASIL, 2011a) }\end{array}$ & $\begin{array}{l}\text { Dispõe sobre a educação especial, o atendimento educacional especializado } \\
\text { e dá outras providências. }\end{array}$ & 2011 \\
\hline
\end{tabular}

Fonte: Dados da pesquisa

(C) Rev. Educ. Perspec.

\begin{tabular}{l|l} 
Viçosa, $M G$ & v.9
\end{tabular}

n.3

p.668-693

set./dez. 2018

eISSN 2178-8359 
Acerca do propósito deste estudo, â ênfase se dará, particularmente, na Convenção sobre os Direitos das Pessoas com Deficiência (ONU, 2006) e no Decreto 7.611/2011 (BRASIL, 2011a).

A CDPD é o primeiro instrumento jurídico de nível internacional à garantia e defesa dos direitos e proteção às pessoas com deficiência. Clarifica que essa responsabilidade é de todos da sociedade civil e não somente dos Estados. Em seu artigo 24, ressalta que a educação é um direito básico e fundamental para o processo de qualificação e empregabilidade. Nesse sentido, promover a inclusão no ensino superior, é algo importantíssimo e, para isso, é necessário que o sistema educacional se constitua de recursos, ferramentas e ações inclusivas para todos. No entanto, a passagem da educação básica para o ensino superior, costuma ser conturbada e excludente em razão da forma como são concebidos e realizados os processos seletivos vestibulares (PSV) nas instituições de ensino superior que ainda permanecem com esse instrumento de seleção, sendo estas instituições, o foco de análise principal deste estudo.

Atentando para a CDPD que sobressalta a igualdade de oportunidades em todos os níveis de ensino, bem como o acompanhamento e intervenção precoce por equipe multiprofissional para que a pessoa com deficiência tenha suas habilidades potencializadas ao máximo, percebe-se que o PSV, dentre outros fatores que não são objetos desse estudo, provoca uma ruptura drástica na vida estudantil daquele que tem SA como no universo mais amplo do diagnóstico do TEA, uma vez que não responde as suas demandas em geral. Inclusive, vale mencionar que esta prerrogativa presente na CDPD, foi empregada, posteriormente, pela Política Nacional de Educação Especial na Perspectiva da Educação Inclusiva (BRASIL, 2008b). Uma dessas demandas, refere-se às dificuldades na área da linguagem, especificamente, em compreender os sentidos e significados dos enunciados das questões, principalmente, aqueles mais extensos e de pouca objetividade.

Estudos apontam que pessoas com SA costumam apresentar dificuldades relacionadas à prosódia, alterações semânticas e pragmáticas, na compreensão metafórica de algumas frases e expressões, bem como na compreensão dos fenômenos linguísticos (MOUSINHO, 2002; SECUNHO, 2005; LEON, 2008; DIAS et al. 2009; SOARES; MOURA, 2009). Importante ressaltar que não se intenciona, neste estudo, generalizar que todos os estudantes com SA apresentarão dificuldades na compreensão de enunciados, mas de destacar que não é incomum esse acontecimento e que nos pressupostos da educação na perspectiva inclusiva, todos os estudantes devem ser contemplados em suas singularidades.

De acordo com a nota técnica emitida pela Diretoria de Avaliação da Educação Básica (BRASIL, 2012), devem ser disponibilizados para a realização do Exame Nacional de Ensino Médio (ENEM), serviços profissionais especializados e recursos de acessibilidade. Contam como serviços prestados aos candidatos com autismo, "o ledor e o transcritor" (BRASIL,

\begin{tabular}{l|c|c|c|c|c|c|} 
(C) Rev. Educ. Perspec. & Viçosa, $M G$ & v.9 & n.3 & p.668-693 & set./dez. 2018 & eISSN 2178-8359 \\
\hline
\end{tabular}


2012, p. 6). No presente documento, o “Auxílio ledor", é destinado à leitura de prova para "pessoas com deficiência visual, deficiência intelectual, autismo, déficit de atenção ou dislexia" (BRASIL, 2012, p. 3). Em razão das dificuldades relacionadas à SA, entende-se que o serviço supracitado, não é suficiente para suprir as demandas apresentadas por esses candidatos. Não obstante, a ampliação da função para não somente ler a prova, mas também, quando necessário, esclarecer dúvidas e auxiliar nos textos, oferecendo sinônimos ou sinais que o ajudem no reconhecimento das expressões idiomáticas, orações e contextos, semelhante ao que é ofertado pelo serviço de "Tradutor-intérprete de LIBRAS", preenche uma lacuna cujo o propósito do serviço de acompanhamento, é proporcionar a igualdade de oportunidades.

Segundo Dias et al. (2009, p. 46-248),

Sujeitos com Síndrome de Asperger e Autismo de alto-funcionamento têm dificuldade em vários aspectos de linguagem pragmática, e isto inclui dificuldade em realizar inferências, especialmente inferências sobre estados mentais. [...]. Há um consenso geral de que estes sujeitos apresentam alterações em relação à linguagem pragmática e de discurso. [...]. Na avaliação da linguagem oral e escrita, o grupo de indivíduos com Síndrome de Asperger caracterizou-se por um desempenho pior do que o grupo de indivíduos de baixo risco para alterações do desenvolvimento nas provas fonoaudiológicas de consciência fonológica, teste de vocabulário por imagem Peabody e prova de compreensão de leitura.

Ainda que a título exploratório, levando-se em conta os estudos já realizados, essa singularidade do estudante com SA, sugere um profissional que o auxilie no processo interpretativo das mensagens presentes nos enunciados, para que possa realizar a avaliação com melhor desempenho, de modo que usufrua da mesma igualdade de oportunidades dos demais candidatos sem o diagnóstico de TEA em sua amplitude. Deste modo, a aplicação e realização do PSV, ocorreria pelo que aqui denomina-se como um "intérprete de enunciados" (IE) para o momento das instruções preliminares, bem como durante o exame, de maneira que possa ser consultado para o esclarecimento de possíveis dúvidas semânticas. $O$ "intérprete de enunciados" aglutinaria os serviços de leitura e auxílio no esclarecimento de dúvidas para a melhor compreensão sobre os enunciados presentes nos processos seletivos e avaliativos em geral, a partir do favorecimento da percepção dos sentidos e significados das expressões idiomáticas, orações, metáforas e contextos.

Em relação às contribuições da CDPD, destacam-se os seguintes aspectos dispostos no quadro 2:

Quadro 2. Convenção sobre os Direitos das Pessoas com Deficiência

\begin{tabular}{|c|l|cc|}
\hline Unidades & \multicolumn{1}{|c|}{ Dizeres da Lei } & \multicolumn{2}{|c|}{$\begin{array}{c}\text { Referência ao termo em } \\
\text { destaque }\end{array}$} \\
\hline Art. 4.3 & $\begin{array}{l}\text { Na elaboração e implementação de legislação e políticas para } \\
\text { aplicar a presente Convenção e em outros processos de tomada }\end{array}$ & $\begin{array}{l}\text { Seja } \\
\text { participação darantida }\end{array}$ & pessoas \\
\hline
\end{tabular}

\begin{tabular}{l|c|c|c|c|c|c|} 
(C) Rev. Educ. Perspec. & Viçosa, $M G$ & v.9 & n.3 & p.668-693 & set./dez. 2018 & eISSN 2178-8359 \\
\hline
\end{tabular}




\begin{tabular}{|c|c|c|}
\hline & $\begin{array}{l}\text { de decisão relativos às pessoas com deficiência, os Estados } \\
\text { Partes realizarão consultas estreitas e envolverão ativamente } \\
\text { pessoas com deficiência, inclusive crianças com deficiência, } \\
\text { por intermédio de suas organizações representativas. }\end{array}$ & $\begin{array}{l}\text { com autismo, suas famílias } \\
\text { e instituições } \\
\text { representativas }\end{array}$ \\
\hline Art. 24 & $\begin{array}{l}\text { Os Estados Partes reconhecem o direito das pessoas com } \\
\text { deficiência à educação. Para efetivar esse direito sem } \\
\text { discriminação e com base na igualdade de oportunidades, os } \\
\text { Estados Partes assegurarão sistema educacional inclusivo em } \\
\text { todos os níveis, bem como o aprendizado ao longo de toda a } \\
\text { vida. }\end{array}$ & $\begin{array}{l}\text { Igualdade de oportunidades } \\
\text { em sistema educacional } \\
\text { inclusivo em todos os } \\
\text { níveis e ao longo da vida. }\end{array}$ \\
\hline Art. 26.1 & $\begin{array}{l}\text { Os Estados Partes tomarão medidas efetivas e apropriadas, } \\
\text { inclusive mediante apoio dos pares, para possibilitar que as } \\
\text { pessoas com deficiência conquistem e conservem o máximo } \\
\text { de autonomia e plena capacidade física, mental, social e } \\
\text { profissional, bem como plena inclusão e participação em todos } \\
\text { os aspectos da vida. Para tanto, os Estados Partes organizarão, } \\
\text { fortalecerão e ampliarão serviços e programas completos de } \\
\text { habilitação e reabilitação, particularmente nas áreas de saúde, } \\
\text { emprego, educação e serviços sociais. }\end{array}$ & $\begin{array}{l}\text { Importância do diagnóstico } \\
\text { e intervenção precoce, } \\
\text { através de equipe } \\
\text { multiprofissional, para que } \\
\text { as pessoas com autismo } \\
\text { possam desenvolver ao } \\
\text { máximo duas habilidades. }\end{array}$ \\
\hline
\end{tabular}

Fonte: Dados da pesquisa

O Decreto $n^{0} 7.611$ (BRASIL, 2011a), por sua vez, dispõe sobre a educação especial, o atendimento educacional especializado e dá outras providências. Ao pontuar a singularidade da pessoa com SA no contexto pós-educação básica, distinguem-se os seguintes artigos e incisos que legitimam a oferta do IE para o estudante com SA, tendo em vista a obrigatoriedade do cumprimento dos documentos normativos existentes, tal como é demonstrado no quadro 3:

Quadro 3. Decreto $n^{\circ} 7.611$ (BRASIL, 2011a)

\begin{tabular}{|c|c|c|}
\hline Unidades & Dizeres da Lei & Referência ao termo em destaque \\
\hline Art. $1^{\circ}$ & $\begin{array}{l}\text { O dever do Estado com a educação das } \\
\text { pessoas público-alvo da educação especial será } \\
\text { efetivado de acordo com as seguintes diretrizes: }\end{array}$ & $\begin{array}{l}\text { É dever do Estado promover condições para que } \\
\text { a educação possa acontecer. }\end{array}$ \\
\hline I & $\begin{array}{l}\text { garantia de um sistema educacional inclusivo } \\
\text { em todos os níveis, sem discriminação e com } \\
\text { base na igualdade de oportunidades. }\end{array}$ & $\begin{array}{l}\text { O processo seletivo vestibular é de passagem } \\
\text { obrigatória para o acesso ao ensino superior. }\end{array}$ \\
\hline II & aprendizado ao longo de toda a vida. & Inclusive pós-graduação. \\
\hline III & $\begin{array}{l}\text { não exclusão do sistema educacional geral sob } \\
\text { alegação de deficiência. }\end{array}$ & $\begin{array}{l}\text { Processos avaliativos excludentes reforçam a } \\
\text { deficiência pela inabilidade em decorrência de } \\
\text { singularidades. }\end{array}$ \\
\hline $\mathrm{V}$ & $\begin{array}{l}\text { oferta de apoio necessário, no âmbito do } \\
\text { sistema educacional geral, com vistas a } \\
\text { facilitar sua efetiva educação. }\end{array}$ & \multirow{3}{*}{ Intérprete de enunciados como apoio. } \\
\hline VI & $\begin{array}{l}\text { adoção de medidas de apoio individualizadas } \\
\text { e efetivas, em ambientes que maximizem o } \\
\text { desenvolvimento acadêmico e social, de acordo } \\
\text { com a meta de inclusão plena. }\end{array}$ & \\
\hline VIII & $\begin{array}{l}\text { apoio técnico e financeiro pelo Poder Público } \\
\text { às instituições privadas sem fins lucrativos, } \\
\text { especializadas e com atuação exclusiva em } \\
\text { educação especial. }\end{array}$ & \\
\hline
\end{tabular}

(C) Rev. Educ. Perspec.

\begin{tabular}{l|l} 
Viçosa, $M G$ & v.9
\end{tabular}

n.3




\begin{tabular}{|c|c|c|}
\hline$\S 1^{\circ}$ & $\begin{array}{l}\text { Para fins deste Decreto, considera-se público- } \\
\text { alvo da educação especial as pessoas com } \\
\text { deficiência, com transtornos globais de } \\
\text { desenvolvimento e com altas habilidades e } \\
\text { superdotação. }\end{array}$ & Inclui-se a Síndrome de Asperger. \\
\hline Art. $3^{\circ}$ & $\begin{array}{l}\text { São objetivos do atendimento educacional } \\
\text { especializado: }\end{array}$ & \multirow{3}{*}{$\begin{array}{l}\text { Intérprete de enunciados como apoio às } \\
\text { singularidades de estudantes com TEA. }\end{array}$} \\
\hline $\mathrm{I}$ & $\begin{array}{l}\text { prover condições de acesso, participação e } \\
\text { aprendizagem no ensino regular e garantir } \\
\text { serviços de apoio especializados de acordo } \\
\text { com as necessidades individuais dos } \\
\text { estudantes. }\end{array}$ & \\
\hline IV & $\begin{array}{l}\text { assegurar condições para a continuidade de } \\
\text { estudos nos demais níveis, etapas e } \\
\text { modalidades de ensino. }\end{array}$ & \\
\hline $\begin{array}{l}\text { Art. } 5^{\circ} \\
\S 2^{\circ}\end{array}$ & $\begin{array}{l}\text { O apoio técnico e financeiro de que trata o } \\
\text { caput contemplará as seguintes ações: } \\
\text { Estruturação de núcleos de acessibilidade nas } \\
\text { instituições federais de educação superior. }\end{array}$ & $\begin{array}{l}\text { As universidades federais devem possuir um } \\
\text { Núcleo de Acessibilidade que auxiliem nas } \\
\text { demandas de alunos com deficiência, inclusive } \\
\text { nas adequações pedagógicas que se fizerem } \\
\text { necessárias. A maioria das universidades } \\
\text { públicas federais já possui o Núcleo de } \\
\text { Acessibilidade. Esse Núcleo é composto por } \\
\text { professores e outros profissionais pertencentes à } \\
\text { área da educação inclusiva. Portanto, é razoável } \\
\text { dizer que as alterações necessárias ao educando } \\
\text { com Síndrome de Asperger, bem como com } \\
\text { outras singularidades, podem ser realizadas tanto } \\
\text { no contexto de sala de aula, como também e, não } \\
\text { menos importante, no processo seletivo para } \\
\text { cursos de graduação, popularmente conhecido } \\
\text { como vestibular. }\end{array}$ \\
\hline$\S 5^{\circ}$ & $\begin{array}{l}\text { Os núcleos de acessibilidade nas instituições } \\
\text { federais de educação superior visam eliminar } \\
\text { barreiras físicas, de comunicação e de } \\
\text { informação que restringem a participação e o } \\
\text { desenvolvimento acadêmico e social de } \\
\text { estudantes com deficiência. }\end{array}$ & $\begin{array}{l}\text { Intérprete de enunciados como apoio às } \\
\text { singularidades de estudantes com TEA. }\end{array}$ \\
\hline
\end{tabular}

Fonte: Dados da pesquisa e Brasil (2011a).

Neste contexto, é de compreensão que os Núcleos de Acessibilidade podem e devem suprir as demandas de alunos com deficiência nas universidades, sendo que nesta categoria, encontram-se as pessoas com TEA (BRASIL, 2008a). Especificamente os incisos do Art. $1^{\circ}$ reportam-se para o entendimento que não se deve colocar obstáculos ou impedimentos para o fluir da educação da pessoa com deficiência, seja em que nível for, educação básica ou ensino superior. Ao contrário deve-se garantir a igualdade de oportunidade em prol de um aprendizado para toda vida, com apoio educacional necessário com vistas a sua permanência na instituição de ensino de modo a facilitar seu processo de aprendizagem, inclusive, com adoção de medidas efetivas que considerem as singularidades do aluno. 
Compreende-se que esses incisos não se remetem apenas ao estudante já aprovado no vestibular e matriculado na instituição de ensino superior. Não obstante, também no processo de passagem do ensino regular da educação básica para o ensino superior, uma vez que os vestibulares no Brasil, tendem a ser homogêneos, classificatórios, padronizados, excludentes e, portanto, não respeitam todo o acervo legislativo que há em prol de uma educação de todos e para todos. Mesmo embora as instituições de ensino possam optar por diferentes formas de realização de seus PSV (tradicional, seriado, agendado, ENEM), o caráter conteudista dos mesmos, inclusive do ENEM como exame de referência para o ingresso em universidades, privilegia alguns candidatos em detrimento de outros menos favorecidos.

Nesse sentido, os PSV se aproximam entre si, como uma ferramenta de parâmetro homogêneo para a seleção de candidatos, da mesma maneira que servem à eliminação de pessoas da oportunidade de seguir sua formação para os níveis mais elevados de ensino. Outrossim, embora não seja foco central deste estudo, cabe dizer que a condição socioeconômica dos alunos também é fator proeminente para êxito e/ou reprovação nos PSV, uma vez que questões cada vez mais complexas e inusitadas são requeridas, possivelmente sendo mais abordadas em cursinhos preparatórios do que no espaço escolar da educação básica.

O vestibular conteudista e padronizado sem o devido recurso que promova igualdade de oportunidades a todos os candidatos, revela-se excludente e não respeita as singularidades das pessoas no contexto da diversidade, aqui em específico, da pessoa com SA. Um processo seletivo, tal como é o vestibular, contradiz a legislação brasileira que orienta a produzir adequações curriculares, didáticas, metodológicas e avaliativas para que ninguém fique de fora de seu direito aos níveis mais elevados de educação. Aliás, como já mencionado anteriormente, é preciso rever sistematicamente os processos pedagógicos de modo a reinventá-los com foco nas demandas do aprendiz com suas singularidades e não apenas adaptar o que já está posto por décadas na coluna vertebral do ensino positivista.

Se o PSV é obrigatório para a ascensão ao ensino superior, ele também deve promover alterações e configurações necessárias às singularidades dos candidatos para que tenham igualdade de oportunidades, equidade e possam pleitear a uma vaga no curso de graduação que aspiram realizar. Se o ensino superior deve respeitar a legislação em vigor e oferecer condições de acesso e permanência do aluno com deficiência à educação, não há coerência em não haver o mesmo rigor quanto ao atendimento às políticas públicas e legislação em prol da educação inclusiva nos PSV. Se o vestibular é a ponte obrigatória de passagem para o ensino superior, então, obrigatoriamente, também deve prover condições e acessibilidade para que o candidato no universo do TEA, possa realizá-lo, tendo seu potencial valorizado, suas limitações respeitadas e suas demandas singulares atendidas. Chama-se à atenção, igualmente, para os exames realizados pelo Sistema de Seleção Unificada (SISU), principal

\begin{tabular}{l|c|c|c|c|c|c|} 
(C) Rev. Educ. Perspec. & Viçosa, $M G$ & v.9 & n.3 & p.668-693 & set./dez. 2018 & eISSN 2178-8359 \\
\hline
\end{tabular}


meio de acesso às instituições federais de ensino, bem como ao Programa Universidade para Todos (PROUNI) e do Fundo de Financiamento Estudantil (FIES) - igualdade de oportunidades, é preciso!

Cabe às instituições de ensino superior, públicas e privadas, ao receberem as inscrições dos candidatos ao PSV, solicitarem informações específicas se o mesmo possui ou não alguma deficiência e, na existência dessa, prover condições para que os exames aplicados contemplem suas singularidades. Deste modo, a universidade não entrará em conflito com o arcabouço legislativo, promovendo condições para que o candidato com SA possa, também, concorrer em base de igualdade e com respeito às diferenças, a uma vaga em cursos de ensino superior.

Há relatos de candidatos com deficiência, inclusive aqueles com SA, sobre as dificuldades de darem continuidade aos seus estudos pela inflexibilidade dos PSV. Estudantes têm evidenciado plenas condições de realizar sua formação universitária em áreas de concentração de seu eixo de interesse. Todavia, casos são relatados sobre as dificuldades para o ingresso, custando o tempo de várias tentativas em PSV. A exemplo, segundo o jovem Wander G. Silva Júnior que participou da audiência pública da Comissão de Defesa dos Direitos da Pessoa com Deficiência: "O processo seletivo não respeita a característica essencial do autista. Esse processo exige que o autista entenda de tudo, à maneira comum, e o avalia" (CDDPD, 2017, p. 6). E ainda acrescenta,

O atendimento está errado, assim como o formato da prova. O Estatuto passou a valer a partir de 2016. O INEP promulgou o edital do ENEM depois do Estatuto. Então, eu imaginei que, quando eu fosse fazer a prova do ENEM de novo, a minha prova viria adaptada, porque o Estatuto diz que ela tem que ser específica à necessidade da pessoa com deficiência. Eu submeti o meu diagnóstico no ato da inscrição e o levei na data da prova. Para a minha surpresa, a minha prova foi igual à de todos (CDDPD, 2017, p. 8).

Contudo, em um processo inclusivo, deve-se levar em conta o potencial, as habilidades, as singularidades e o conhecimento acumulado do candidato, oferecendo-lhe os recursos necessários para expor, demonstrar e registrar seu conhecimento prévio (CDDPD, 2017).

Vários aprendizes têm vencido muitos desafios impostos pelo próprio quadro sintomático da $\mathrm{SA}$, mas também têm superado às dificuldades impostas por uma sociedade que não foi planejada para respeitar as diferenças de cada um (OLIVATI; LEITE, 2017). Infelizmente, as instituições de ensino têm sido, em diversas circunstâncias, locais de sofrimento e território de luta incessante para a pessoa com deficiência. Segundo o especial produzido pelo Cotidiano UFSC que relata histórias de estudantes com autismo que ingressaram na Universidade,

\begin{tabular}{l|c|c|c|c|c|c|} 
(C) Rev. Educ. Perspec. & Viçosa, $M G$ & v.9 & n.3 & p.668-693 & set./dez. 2018 & eISSN 2178-8359 \\
\hline
\end{tabular}


Os desafios se tornaram maiores no Ensino Superior, em que os métodos avaliativos e a rotina são mais sujeitas a variação. Por levar um tempo maior que os outros colegas para realizar os trabalhos acadêmicos, A. ficava bastante desgastado. Ele também não conseguia dormir, e por isso, precisou tomar um ansiolítico para dar sequência na agenda que tinha as páginas dobradas a cada tarefa cumprida (NORA; KONS; AMORIM, 2016, s.p.).

Com árduo apoio de seus familiares e com disponibilidade e entendimento de instituições de educação básica, favorecedoras do processo de inclusão, eles têm galgado da educação infantil até o ensino médio (INSTITUTO UNIBANCO, 2016). Não obstante, é preciso avançar para uma educação efetivamente inclusiva, também no ensino superior. Neste sentido, a Profa. Patrícia Raposo, Diretora de Políticas de Educação Especial (SECADI/MEC), com relação às solicitações do jovem Wander, responde:

Eu entendo que essas singularidades que o Wander coloca no processo de seleção do ENEM estão sendo pautadas continuamente. Como Diretora de Políticas de Educação Especial, entendo a transversalidade da atuação da educação especial, que não atua como uma modalidade de ensino paralelo, mas sim dessa forma transversal, contínua e dinâmica nos sistemas de ensino, para que eles possam dar respostas adequadas a todos os alunos. [...] Então, Wander, nós estamos muito preocupados com essa questão. Eu gostaria de dizer a você que a Diretoria da qual eu sou titular, a SECADI, e o Ministério da Educação têm preocupações com essa questão. Nós estamos buscando, na medida do possível, colocar como desafios essas questões do INEP em relação ao ENEM. [...]. Em relação ao espectro autista é um grande desafio, justamente por causa das singularidades que você expôs. Então, nós temos que organizar, sem dúvida um grupo de trabalho com especialistas. Em algum momento, nós sabemos que isso precisa ser, de alguma forma, uniformizado e unificado, para atender a todas as pessoas do espectro autista. Isso é bem complexo (CDDPD, 2017, p. 32).

No entanto, como exposto acima, em razão da falta de políticas públicas mais contundentes, esses mesmos aprendizes têm se deparado com dificuldades desnecessárias para ultrapassar as barreiras do PSV que rompe com as ações pró-inclusão, barra e dificulta o acesso ao ensino mais elevado em cursos superiores. Segundo o documento Política Nacional de Educação Especial na Perspectiva da Educação Inclusiva do Ministério da Educação:

Na perspectiva da educação inclusiva, cabe destacar que a educação especial tem como objetivo assegurar a inclusão escolar de alunos com deficiência, transtornos globais do desenvolvimento e altas habilidades/superdotação nas turmas comuns do ensino regular, orientando os sistemas de ensino para garantir o acesso ao ensino comum, a participação, aprendizagem e continuidade nos níveis mais elevados de ensino; a transversalidade da educação especial desde a educação infantil até a educação superior; a oferta do atendimento educacional especializado; a formação de professores para o atendimento educacional especializado e aos demais profissionais da educação, para a inclusão; a participação da família e da comunidade; a acessibilidade arquitetônica, nos transportes, nos mobiliários, nas comunicações e informações; e a articulação intersetorial na implementação das políticas públicas (BRASIL, 2008b, grifo nosso).

Para haver a continuidade nos níveis mais elevados de ensino, como é o caso do ensino superior para aqueles que concluíram o ensino médio, é preciso compreender que esses

\begin{tabular}{l|c|c|c|c|c|c} 
(C) Rev. Educ. Perspec. & Viçosa, $M G$ & v.9 & n.3 & p.668-693 & set./dez. 2018 & eISSN 2178-8359 \\
\hline
\end{tabular}


aprendizes não devem ser impedidos de seguirem em frente pelo obstáculo de um processo seletivo de parâmetro excludente que não leva em conta suas singularidades. Segundo o jovem com SA, Victor Mendonça, estudante de jornalismo,

\begin{abstract}
O aluno autista tem uma série de direitos legais que não devem ser ignorados e acionados quando houver necessidade. Um deles é adaptação no plano de ensino. O conteúdo cobrado é o mesmo, mas a forma tem de ser diferente porque o nosso cérebro tem funcionamento fora do padrão e o autista se desgasta muito mais para realizar as mesmas atividades que os colegas neurotípicos. Essa exaustão ocorre, em especial, porque despendemos um grande esforço para decodificar as informações e estímulos. As pessoas não autistas não conhecem essa sensação, então é comum aos educadores que tentem extrair mais um pouco de esforço do autista do que ele dá conta (MENDONÇA, 2016, s.p.)
\end{abstract}

Conforme as informações dispostas anteriormente, acerca da presença de aprendizes com TEA (APA, 2013) no decorrer da Educação Básica, o aumento significativo de matriculas no ensino regular, justifica e demanda que novos processos pedagógicos sejam construídos rumo ao ensino superior (BRASIL, 2012; 2015b; 2015c).

A Lei $n^{\circ} 13.146$ (BRASIL, 2015a) que institui a Lei Brasileira de Inclusão da Pessoa com Deficiência, é destinada a assegurar e a promover, em condições de igualdade, o exercício dos direitos e das liberdades fundamentais da pessoa com deficiência, visando a sua inclusão social e cidadania. A Lei tem como base a CDPD (BRASIL, 2009) e seu Protocolo Facultativo, ratificados pelo Congresso Nacional por meio do Decreto Legislativo $n^{\circ} 186$ (BRASIL, 2008a), em conformidade com o procedimento previsto no $\S 3^{\circ}$ do art. $5^{\circ}$ da Constituição Federal (BRASIL, 1988). Entende-se que, no que implica à pessoa com SA, segundo o Art. $3^{\circ}$, para fins de aplicação desta Lei, consideram-se os parâmetros destacados no quadro 4:

Quadro 4. Lei $n^{\circ} 13.146$ (BRASIL, 2015a)

\begin{tabular}{|c|c|c|}
\hline Unidades & Dizeres da Lei & $\begin{array}{c}\text { Referência ao termo em } \\
\text { destaque }\end{array}$ \\
\hline III & $\begin{array}{l}\text { Tecnologia assistiva ou ajuda técnica: produtos, } \\
\text { equipamentos, dispositivos, recursos, metodologias, } \\
\text { estratégias, práticas e serviços que objetivem promover a } \\
\text { funcionalidade, relacionada à atividade e à participação da } \\
\text { pessoa com deficiência ou com mobilidade reduzida, } \\
\text { visando à sua autonomia, independência, qualidade de visa } \\
\text { e inclusão social. }\end{array}$ & $\begin{array}{l}\text { Intérprete de enunciados se } \\
\text { enquadra nos quesitos: ajuda } \\
\text { técnica, recursos, metodologias, } \\
\text { estratégias, práticas e serviços. }\end{array}$ \\
\hline IV & $\begin{array}{l}\text { barreiras: qualquer entrave, obstáculo, atitude ou } \\
\text { comportamento que limite ou impeça a participação } \\
\text { social da pessoa, bem como o gozo, a fruição e o exercício } \\
\text { de seus direitos à acessibilidade, à liberdade de movimento } \\
\text { e de expressão, à comunicação, ao acesso à informação, à } \\
\text { compreensão, à circulação com segurança, entre outros, } \\
\text { classificadas em: d) barreiras nas comunicações e na } \\
\text { informação: qualquer entrave, obstáculo, atitude ou } \\
\text { comportamento que dificulte ou impossibilite a }\end{array}$ & $\begin{array}{l}\text { Dificuldades para a compreensão } \\
\text { de enunciados dificulta e entrava o } \\
\text { processo comunicativo e o acesso } \\
\text { à igualdade de oportunidades em } \\
\text { níveis mas elevados de ensino. }\end{array}$ \\
\hline
\end{tabular}

\begin{tabular}{l|l|l} 
Viçosa, $M G$ & v.9 & n.3
\end{tabular}

p.668-693

set./dez. 2018

eISSN 2178-8359 


\begin{tabular}{|c|c|c|}
\hline & $\begin{array}{l}\text { expressão ou o recebimento de mensagens e de } \\
\text { informações por intermédio de sistemas de comunicação e } \\
\text { de tecnologia da informação; e) barreiras atitudinais: } \\
\text { atitudes ou comportamentos que impeçam ou } \\
\text { prejudiquem a participação social da pessoa com } \\
\text { deficiência em igualdade de condições e oportunidades } \\
\text { com as demais pessoas; f) barreiras tecnológicas: as que } \\
\text { dificultam ou impedem o acesso da pessoa com } \\
\text { deficiência às tecnologias. }\end{array}$ & \\
\hline VI & $\begin{array}{l}\text { adaptações razoáveis: adaptações, modificações e ajustes } \\
\text { necessários e adequados que não acarretem ônus } \\
\text { desproporcional e indevido, quando requeridos em cada } \\
\text { caso, a fim de assegurar que a pessoa com deficiência } \\
\text { possa gozar ou exercer, em igualdade de condições e } \\
\text { oportunidades com as demais pessoas, todos os direitos e } \\
\text { liberdades fundamentais. }\end{array}$ & $\begin{array}{l}\text { Os PSV, bem como os demais } \\
\text { processos avaliativos, necessitam } \\
\text { sofrer adaptações, modificações e } \\
\text { ajustes para não serem um } \\
\text { empecilho ao acesso, permanência } \\
\text { e garantia de oportunidades no } \\
\text { ensino superior. }\end{array}$ \\
\hline
\end{tabular}

Fonte: Dados da pesquisa e Brasil (2015a).

E, ainda, o Art. 24 recomenda que "e) Medidas de apoio individualizadas e efetivas sejam adotadas em ambientes que maximizem o desenvolvimento acadêmico e social, de acordo com a meta de inclusão plena" (BRASIL, 2015a).

Cabe dizer que singularidades visíveis aos olhos, tal como é a deficiência visual, a deficiência física ou auditiva, enunciam com evidência as demandas desses aprendizes ou candidatos de processos seletivos diversos. Entretanto, as singularidades daquele com TEA (APA, 2013) são diferenciadas e não visíveis aos olhos. Elas dizem respeito às dificuldades no processo de interação social, na comunicação, na compreensão de sentidos e significados, no perceber claramente as situações ao seu redor, na codificação de expressões faciais que exprimem sentimentos diversos.

Claro está que não se deve exigir que um candidato com deficiência visual, para ser aprovado, leia e realize uma prova pertencente ao conjunto de avaliações de seu PSV, uma vez que ele não tem essa capacidade e, em tal exigência, o mesmo se encontraria em uma situação de desigualdade de oportunidades frente aos demais candidatos sem deficiência visual. Similar, não se deve requerer que um candidato com SA faça sua prova sem algum recurso ou serviço que lhe auxilie em sua dificuldade gerada por sua singularidade, no caso, relacionada à compreensão de enunciados pelo déficit, principalmente, no entendimento de sentidos e significados presentes nas questões avaliativas (MOUSINHO, 2002; SECUNHO, 2005; LEON, 2008; DIAS et al. 2009; SOARES; MOURA, 2009).

Nesse sentido, enquanto a pessoa com deficiência visual pode solicitar um ledor para sua prova ou da mesma feita em Braile, a pessoa com surdez pode requerer um intérprete de Língua Brasileira de Sinais para sua avaliação, bem como, a pessoa com deficiência motora pode necessitar de um tempo maior para ter condições de redigir sua prova ou mesmo, precisar de um notebook. Outrossim, levando-se em conta as dificuldades e singularidades já

\begin{tabular}{l|l|l|l|l|l|l} 
(ㄱ) Rev. Educ. Perspec. & Viçosa, $M G$ & v.9 & n.3 & p.668-693 & set./dez. 2018 & eISSN 2178-8359 \\
\hline
\end{tabular}


abordadas no texto, um candidato com SA também pode necessitar de um IE que o auxilie a compreender os sentidos e significados presentes nesse corpo da questão para que tenha condições de realizar aquilo que lhe foi solicitado. A exemplo, Autism\&Uni (2013, p. 5) menciona em seu manual para práticas de apoio a estudantes com TEA, a disponibilidade de um assistente em exames e estudos para esclarecimento quanto à formulações ambíguas que podem confundir o entendimento preciso das questões, por parte do aluno. De acordo com o manual, essa ação já é promovida por algumas instituições de ensino superior da Europa. Não apenas o assistente, mas também a permissão para o uso de computadores portáteis para a realização de exames escritos.

O que aqui se nomeia de IE, para especificarmos a necessidade mais comum em aprendizes e candidatos com SA, não tem a intenção de facilitar ou minimizar a complexidade do processo avaliativo. Porém, tem o objetivo de tornar a avaliação acessível a quem, cuja singularidade, demanda alterações específicas para a compreensão e melhor entendimento dos sentidos e significados de enunciados. Diz respeito a seguir a lógica do conjunto legislativo em prol da educação inclusiva, onde se valoriza o potencial da pessoa com deficiência e se respeita as limitações impostas pela singularidade.

Este auxílio às pessoas com SA não faz com que o acesso à educação superior fique mais fácil para elas ou que desfrutem de privilégios. Há que se lembrar, permanentemente, que as pessoas com deficiência, as pessoas com SA, estão a todo tempo procurando se adaptar à lógica, ao fluir das exigências de uma sociedade organizada, majoritariamente, de forma padronizada e homogênea, uma sociedade excludente que tem dificuldades e resistência em lidar com as diferenças, apesar das lutas e manifestos permanentes dos diversos e distintos movimentos sociais (SOUZA, 2008).

Convém dizer que se levando em conta as singularidades da pessoa com SA, entre elas, os interesses restritos pronunciados, é comum que essa pessoa busque uma ocupação, uma profissão focada em seu eixo de interesse (ORRÚ, 2016). Logo, candidatos a cursos superiores poderão ter a oportunidade de alcançarem níveis mais elevados de educação e também de se tornarem profissionais de excelência se estiverem focados em seu eixo de interesse, também chamado de hiperfoco (SACKS, 1995). Portanto, não deve ser a inflexibilidade do PSV, a barreira a dificultar ou impedir a graduação desse candidato em questão, muito menos, o motivo de desperdício de talentos que favoreçam condições para o trabalho.

Segundo o Artigo $4^{\circ}$ da Lei $n^{\circ} 13.146$ (BRASIL, 2015a), "toda pessoa com deficiência tem direito à igualdade de oportunidades com as demais pessoas e não sofrerá nenhuma espécie de discriminação".

\begin{tabular}{l|l|l|l|l|l|l} 
(C) Rev. Educ. Perspec. & Viçosa, $M G$ & v.9 & n.3 & p.668-693 & set./dez. 2018 & eISSN 2178-8359 \\
\hline
\end{tabular}


$\S 1^{\circ}$ Considera-se discriminação em razão da deficiência toda forma de distinção, restrição ou exclusão, por ação ou omissão, que tenha o propósito ou o efeito de prejudicar, impedir ou anular o reconhecimento ou o exercício dos direitos e das liberdades fundamentais de pessoa com deficiência, incluindo a recusa de adaptações razoáveis e de fornecimento de tecnologias assistivas (BRASIL, 2015a, Art. $\left.4^{\circ}\right)$.

Ao omitir ou negar um IE ao candidato com SA, nega-se o direito previsto no referido artigo, uma vez conhecidas suas singularidades (MOUSINHO, 2002; SECUNHO, 2005; LEON 2008; DIAS et al. 2009; SOARES; MOURA, 2009; APA, 2013; AUTISM\&UNI, 2013).

Resta colocar que a SA pode se manifestar com outras comorbidades ${ }^{\mathrm{ii}}$ ou condições clínicas associadas. Nesses casos, as dificuldades para o candidato ao PSV podem aumentar. A exemplo, se um candidato com SA também possui dislexia, ele poderá ainda ter uma maior dificuldade relacionada à leitura, escrita e compreensão de textos (FRITH, 2013).

Se a comorbidade for relacionada à discalculia (popularmente conhecida como a versão matemática da dislexia), as dificuldades de executar operações de matemática poderão estar substancialmente presentes. Embora reconheça os números, há dificuldades para o estabelecimento de relações entre eles e da identificação e compreensão dos símbolos matemáticos (FARREL, 2015).

Em tempo, há que se dizer que o atendimento diferenciado em provas de seleção é um direito da pessoa com deficiência. Segundo o Decreto no 5.296 (BRASIL, 2004), todos têm direito a instrumentos, equipamentos ou tecnologias adaptadas para promover sua autonomia e favorecer à igualdade de oportunidades.

Importante ressaltar que desde 2012, provas como o ENEM, vêm adotando medidas de atendimento diferenciado para candidatos com dislexia (BRASIL, 2012). Já em 2015 as provas do ENEM passaram a oferecer auxílio para candidatos com dislexia e discalculia (BRASIL, 2015c). Na edição de 2017, participantes com surdez poderão optar pela "Prova em Vídeo Libras" (BRASIL, 2017c). A intenção do INEP, é tornar a educação cada vez mais acessível ao cidadão brasileiro com alguma singularidade. Segue, portanto, a prerrogativa da Lei $\mathrm{n}^{\circ} 13.146$ (BRASIL, 2015a), de que a educação constitui direito da pessoa com deficiência, bem como assegurados um sistema educacional inclusivo em todos os níveis e aprendizado ao longo de toda a vida, de forma a alcançar o máximo desenvolvimento possível de seus talentos e habilidades físicas, sensoriais, intelectuais e sociais, segundo suas características, interesses e necessidades de aprendizagem.

Apesar dos avanços na legislação à inclusão escolar e acadêmica de pessoas com deficiência, ainda há muito que se fazer, muitas barreiras a romper, preconceitos e discriminações a eliminar. No caso das pessoas com SA, o desafio é singular, pois suas singularidades não são

\begin{tabular}{l|c|c|c|c|c|c|} 
() Rev. Educ. Perspec. & Viçosa, MG & v.9 & n.3 & p.668-693 & set./dez. 2018 & eISSN 2178-8359 \\
\hline
\end{tabular}


visíveis aos olhos e, sim, percebidas pela observação do comportamento social. Não obstante, cada pessoa com SA pode ter interesses restritos, potenciais e limitações bem distintas de outras pessoas com o mesmo quadro sintomático. Portanto, o que serve em recursos para um candidato, pode não ser exatamente a demanda do outro. Por isso, a importância do processo de inscrição para o PSV, oferecer opções diversas para que o candidato tenha sua necessidade específica atendida para o dia da avaliação.

Os laudos médicos se pautam em critérios diagnósticos e são exigidos para o atendimento às solicitações de estudantes com distintas singularidades para a realização de exames avaliativos, inclusive, para o ENEM (BRASIL, 2017b). É importante perceber que, se dentro dos critérios diagnósticos (CID 10 e DSM V) para o TEA, afirma-se que essa pessoa apresenta interesses restritos, deve-se levar em conta que o candidato terá muito que se esforçar e se ajustar às exigências de um PSV padronizado e homogêneo que desconsidera suas singularidades. Contudo, seria muito mais lógico, para os candidatos com SA, que o PSV fosse vocacionado, uma vez que seu potencial, seu conhecimento, suas habilidades cognitivas estão muito mais focadas em seu eixo de interesse, podendo revelar-se um talentoso profissional na área por ele escolhida. A propósito, a configuração de um processo de oportunidades de ingresso no ensino superior ao invés de um PSV, a partir de questões variadas, consoante o curso aspirado pelo candidato e foco no eixo de interesse, poderia ser um caminho mais razoável de acesso ao ensino superior para todos os estudantes, independentemente de suas diferenças singulares.

\section{CONCLUSÕES}

A SA, atualmente enquadrada no bojo dos TEA (APA, 2013), está relacionada às alterações qualitativas na interação social, interesses restritos, sensibilidade à mudanças e rotinas, além de déficits de comunicação. As dificuldades ou limitações relacionadas à comunicação dizem respeito às inadequações de respostas em conversas, à inabilidade em interpretar sentidos e significados tanto nas relações não-verbais como na interpretação de textos. A SA pode se associar a outras condições clínicas, ocasionando um quadro de comorbidades que pode se apresentar na forma de diversas singularidades, além daquelas próprias da síndrome.

O Brasil possui um acervo legislativo e orientador importante em prol da inclusão da pessoa com deficiência. Dentre os vários documentos existentes, destacam-se a Convenção sobre os Direitos das Pessoas com Deficiência (ONU, 2006) e Decreto 7.611/2011 (BRASIL, 2011), conforme exposto no texto. Esses documentos fundamentam as políticas públicas afirmativas para a inclusão escolar e acadêmica do aluno com deficiência. Portanto, destina-se, igualmente, aos alunos com SA em todas as modalidades e níveis de ensino propostas.

\begin{tabular}{l|c|c|c|c|c|c|} 
(C) Rev. Educ. Perspec. & Viçosa, $M G$ & v.9 & n.3 & p.668-693 & set./dez. 2018 & eISSN 2178-8359 \\
\hline
\end{tabular}


Não obstante, os PSV permanecem excludentes e rompem com o segmento da inclusão construído ao longo dos anos. Os PSV, da forma como são realizados atualmente, colocam-se como obstáculos e dificultam o candidato com SA a dar continuidade em seus estudos no ensino superior, tal como a legislação orienta que deva acontecer. Como consequência, talentos diversos são desperdiçados todos os anos devido ao cumprimento de exigências que obscurecem o direito à igualdade de oportunidades ao acesso à educação superior, por desconsiderarem as dificuldades e limitações decorrentes das singularidades da SA. Desconsideram as limitações da mesma forma que ignoram o foco em interesses restritos desses candidatos, muitas vezes, impedindo que essa pessoa realize sua graduação em sua área de interesse, cujo resultado, é a perda possível de um profissional de excelência que poderia, dentro de seu eixo de interesse, inserir-se no mundo do trabalho e, desta forma, sustentar-se e ser um cidadão autônomo.

Conclui-se que, perante a legislação referente à educação inclusiva, o candidato com SA deve ter seu direito assegurado a um PSV apropriado às suas singularidades, para que tenha condições de concorrer a uma vaga em cursos superiores, dentro de um contexto de igualdade de oportunidades e com equidade. Para o estudante com SA, a oferta do profissional IE pode ser um recurso favorecedor do acesso e permanência na educação superior, por dirimir as barreiras geradas pelas singularidades pertinentes à linguagem.

Cabe às instituições de ensino superior, tanto públicas como privadas, reconhecerem a necessidade de mudanças significativas para o PSV. Alterações necessárias para que não sejam obstruídas as conquistas e os esforços realizados pela pessoa com SA e seus familiares, ao longo dos anos, pela inflexibilidade da aplicação das avaliações. Similar, a não ofuscarem o trabalho pedagógico realizado durante toda a educação básica junto ao aprendiz com SA, por meio da barreira de PSV que desconsideram todo o aprendizado acumulado por anos de estudo e reelaborações dos processos pedagógicos.

PSV que não respeitam as políticas públicas tampouco as legislações vinculadas ao direito à educação na perspectiva inclusiva, marginalizam e excluem pessoas com SA, dentre outras do conjunto das minorias, da oportunidade de continuarem seus estudos em sua área de interesse, certamente focada desde à infância, podendo destiná-las a serem dependentes de seus familiares, não apenas no contexto financeiro, mas também no âmbito emocional, usurpando-lhes a possibilidade de serem cidadãos autônomos, produtivos e, não menos importante, felizes e satisfeitos com suas conquistas. 


\section{REFERÊNCIAS}

AMORIM, Letícia Calmon Drummond; ASSUMPÇÃO JUNIOR, Francisco Batista. O conceito de morte e a Síndrome de Asperger. Estudos de Psicologia, Campinas, v. 29, n. 3, p. 363-370, jul./set. 2012. Disponível em: http://www.scielo.br/pdf/estpsi/v29n3/06.pdf. Acesso em: 30 maio 2018.

APA. American Psychiatric Association. Manual de Diagnóstico e Estatística de Distúrbios Mentais DSM-IV. São Paulo: Manole, 1994.

APA. American Psychiatric Association. Manual de Diagnóstico e Estatística de Distúrbios Mentais DSM-V. São Paulo: Arlington, VA, 2013.

ASPERGER, Hans. Autistic psychopathy in childhood. In: FRITH, Uta. Autism and Asperger syndrome. United Kingdom: Cambridge University Press, 1944. P. 37-92.

AUTISM\&UNI. Best practice for professionals supporting autistic students within or outside HE Institutions. UK: Autism\&Uni, 2013. Disponível em: https://goo.gl/pPr1LS. Acesso em: 17 jul. 2018.

BAUER, Stephen. Asperger Syndrome - trought the lifespan. New York, The developmental unit, Genesee Hospital Rochester, 1996. Disponível em: https://goo.gl/pGN4L5. Acesso em: 18 jul. 2018.

BBC. 'Só descobri que tinha autismo depois de adulta'. BBC. 01 de abril de 2018. 2018. Disponível em: https://www.bbc.com/portuguese/geral-43549847. Acesso em: 17 jul. 2018.

BRASIL. Constituição da República Federativa do Brasil. Presidência da República. Brasília: DF, 1988. Disponível em: http://www2.senado.leg.br/bdsf/bitstream/handle/id/508200/CF88_EC85.pdf. Acesso em: 18 abr. 2018.

BRASIL. Convenção sobre os Direitos das Pessoas com Deficiência. Presidência da República. Brasília: DF, 2009. Disponível em: http://www.planalto.gov.br/ccivil_03/_ato2007-2010/2009/decreto/d6949.htm. Acesso em: 18 abr. 2018.

BRASIL. Decreto 5.626, de 22 de dezembro de 2005. Presidência da República. Brasília: DF, 2005. Disponível em: http://www.planalto.gov.br/ccivil_03/_ato20042006/2005/decreto/d5626.htm. Acesso em: 18 abr. 2018.

BRASIL. Decreto Legislativo no 186, de 09 de julho de 2008. Senado Federal. Brasília: DF, 2008a. Disponível em: http://portal.mec.gov.br/dmdocuments/decreto186.pdf. Acesso em: 18 abr. 2018. 
BRASIL. Decreto $\mathbf{n}^{\mathbf{0}}$ 5.296, de 2 de dezembro de 2004. Presidência da República. Brasília: DF, 2004. Disponível em: http://www.planalto.gov.br/ccivil_03/_ato20042006/2004/decreto/d5296.htm. Acesso em: 18 abr. 2018.

BRASIL. Decreto no 6.949, de 25 de agosto de 2009. Presidência da República. Brasília: DF, 2009. Disponível em: http://portal.mec.gov.br/dmdocuments/decreto6949_seesp.pdf. Acesso em: 19 abr. 2018.

BRASIL. Decreto no 7.611, de 17 de novembro de 2011. Presidência da República. Brasília: DF, 2011. Disponível em: http://www.planalto.gov.br/ccivil_03/_ato20112014/2011/decreto/d7611.htm. Acesso em: 30 maio 2018.

BRASIL. Lei no 13.146, de 6 de julho de 2015. Presidência da República. Brasília: DF, 2015a. Disponível em: http://www.planalto.gov.br/ccivil_03/_ato20152018/2015/lei/113146.htm. Acesso em: 19 jul. 2018.

BRASIL. Censo da Educação Superior 2011 - Resumo Técnico. Brasília: Ministério da Educação. Instituto Nacional de Estudos e Pesquisas Educacionais Anísio Teixeira, 2013. Disponível em: http://download.inep.gov.br/download/superior/censo/2011/resumo_tecnico censo_educacao_superior_2011.pdf. Acesso em: 17 jul. 2018

BRASIL. Deficientes auditivos e surdos terão mais recursos para fazer o Enem em 2017. Brasília: Ministério da Educação. Instituto Nacional de Estudos e Pesquisas Educacionais Anísio Teixeira. 2017c. Disponível em: https://goo.gl/kAtVSi. Acesso em: 17 jul. 2018.

BRASIL. Orientações para implementação da política de educação especial na perspectiva da educação inclusiva. Brasília: Ministério da Educação, 2015b. Disponível em: https://goo.gl/18zFzN. Acesso em: 17 jul. 2018.

BRASIL. Censo da Educação Superior 2016. Brasília: Instituto Nacional de Estudos e Pesquisas Educacionais Anísio Teixeira. 2017a. Disponível em: https://goo.gl/jLHC7C. Acesso em: 18 abr. 2018.

BRASIL. INEP/MEC divulga Censo Escolar 2017. Brasília: Instituto Nacional de Estudos e Pesquisas Educacionais Anísio Teixeira. 2018. Disponível em: https://goo.gl/KiwJKc. Acesso em: 18 abr. 2018.

BRASIL. Edital no 13, de 7 de abril de 2017 - Exame Nacional do Ensino Médio - ENEM. 2017. Brasília: Instituto Nacional de Estudos e Pesquisas Educacionais Anísio Teixeira, 2017b. Disponível em: https://goo.gl/YKWK3k. Acesso em: 17 jul. 2018.

BRASIL. O atendimento diferenciado no ENEM. Nota Técnica. Brasília: Ministério da Educação. Instituto Nacional de Estudos e Pesquisas Educacionais Anísio Teixeira. 2012. Disponível em: https://goo.gl/5XQ24k. Acesso em: 16 jul. 2018.

\begin{tabular}{|l|l|l|l|l|l|l|} 
(C) Rev. Educ. Perspec. & Viçosa, $M G$ & v.9 & n.3 & p.668-693 & set./dez. 2018 & eISSN 2178-8359 \\
\hline
\end{tabular}


BRASIL. Edital no 6, de 15 de maio de 2015 - Exame Nacional Do Ensino Médio - ENEM. 2015. Brasília: Instituto Nacional de Estudos e Pesquisas Educacionais Anísio Teixeira., 2015c. Disponível em: https://goo.gl/63kmMR. Acesso em: 17 jul. 2018.

BRASIL. Política Nacional de Educação Especial na perspectiva da Educação Inclusiva. Senado Federal. Brasília: DF, 2008b. Disponível em: http://portal.mec.gov.br/arquivos/ pdf/politicaeducespecial.pdf. Acesso em: 18 abr. 2018.

CDC. Centers for Disease Control and Prevention. Changes in Prevalence of Parentreported Autism Spectrum Disorder in School-aged U.S: Children: 2007 to 2011-2012. National Health Statistics Reports, USA, 20 mar. 2013.

CDC. Centers for Disease Control and Prevention. Estimated Prevalence of Children With Diagnosed Developmental Disabilities in the United States, 2014-2016. NCHS Data Brief, Hyattsville, n. 291, November 2017. Disponivel em: https://www.cdc.gov/nchs/data/ databriefs/db291.pdf. Acesso em: 18 abr. 2018.

CDDPD. Comissão de Defesa dos Direitos das Pessoas com Deficiência. Debate sobre os desafios na escola e no trabalho para o autista. Audiência Pública - Reunião no: 0415/17. Brasília: Câmara Legislativa. 04 maio 2017. p. 57. Disponível em: https://goo.gl/EJsWmf. Acesso em: 16 jul. 2018.

CONFEDERAÇÃO ASPERGER ESPANHA. Origen del síndrome y epidemiología. Asperger.es. 2017. Disponível em: https://www.asperger.es/asperger_origen_ epidemiologia.html. Acesso em: 18 abr. 2018.

CZELUSNIAK, Adriana. Adultos convivem com o autismo sem saber. Vida e Cidadania. Gazeta do Povo. 2013. Disponível em: https://goo.gl/4w8UfY. Acesso em: 17 jul. 2018.

DIAS, Karin Ziliotto et al. Avaliação da linguagem oral e escrita em sujeitos com Síndrome de Asperger. Rev. CEFAC. V. 11, supl. 2, p. 240-250, mar. 2009. Disponível em: https://goo.gl/Mq5BAC. Acesso em: 16 jul. 2017.

EAG. Education at a Glance. Brazil - Country Note - Education at a Glance 2017: OECD Indicators. Secretary-General of the OECD, 2017. Disponível em: https://goo.gl/PM2kXq. Acesso em: 17 jul. 2018.

FARRELL, Michael. Dislexia e outras dificuldades de aprendizagem específicas: Guia do Professor. 2. ed. Porto Alegre: ArtMed, 2015.

FRITH, Uta. Autism and Dyslexia: A Glance Over 25 Years of Research. Perspect. Psychol Sci. v. 8, n. 6, p. 670-672, nov. 2013. Disponível em: https://www.ncbi.nlm.nih.gov/pubmed/ 25076978. Acesso em: 17 jul. 2018.

GIL, Antônio Carlos. Como elaborar projetos de pesquisa. 4 ed. São Paulo: Atlas, 2002.

\begin{tabular}{l|c|c|c|c|c|c} 
(C) Rev. Educ. Perspec. & Viçosa, $M G$ & v.9 & n.3 & p.668-693 & set./dez. 2018 & eISSN 2178-8359 \\
\hline
\end{tabular}


GOESSLER, Danieli de Cássia Barreto. Inclusão no ensino superior: o que revelam os microdados do censo da educação superior no período 2009- 2012. X ANPED SUL, Florianópolis, out. 2014, p. 1-16. Disponível em: http://xanpedsul.faed.udesc.br/arq_pdf/7920.pdf. Acesso em: 17 jul. 2018.

INSTITUTO UNIBANCO. Inclusão aumenta, mas acesso ao ensino médio ainda é desafio. Aprendizagem Em Foco, ${ }^{\circ}$ 15, ago. 2016. Disponível em: https://goo.gl/i2Td7F. Acesso em: 17 jul. 2018.

KELTER, M. Autism and Depression: managing self-hatred (Asperger's, ASD). Invisiblestrings, 2014. Disponível em: http://theinvisiblestrings.com/autism-depressionmanaging-self-hatred-aspergers-asd/. Acesso em: 17 jul. 2018.

KLIN, Ami. Asperger syndrome: an update. Rev. Bras. Psiquiatr. São Paulo, v. 25, n. 2, p. 103-109, jun. 2003. Disponível em: http://www.scielo.br/scielo.php?script=sci_arttext\&pid= S1516-44462003000200011\&lng=en\&nrm=iso. Acesso em: 18 jul. 2018.

KLIN, Ami. Autismo e síndrome de Asperger: uma visão geral. Rev. Bras. Psiquiatr. São Paulo, v. 28, supl. 1, p. 3-11, maio 2006. Disponível em: http://www.scielo.br/scielo.php? script=sci_arttext\&pid=S1516-44462006000500002\&lang=pt. Acesso em: 16 jul. 2018.

LEON, Viviane Costa de. A compreensão e a produção de enunciados metafóricos em crianças com transtornos globais do desenvolvimento. 2008. $140 \mathrm{f}$. Tese (Doutorado em Psicologia do Desenvolvimento) - Instituto de Psicologia, Universidade Federal do Rio Grande do Sul, RS, 2008.

LOPES-HERRERA, Simone Aparecida. Avaliação de estratégias para desenvolver habilidades comunicativas verbais em indivíduos com autismo de alto funcionamento e síndrome de Asperger. 2005. 181 f. Tese (Doutorado em Educação Especial) Universidade Federal de São Carlos: UFSCar, São Carlos, SP, 2005.

LYALL, Kristen et al. The Changing Epidemiology of Autism Spectrum Disorders. Annual Review of Public Health. USA, v. 38, n. 1, p. 81-102, mar. 2017. Disponível em: https://www.annualreviews.org/doi/10.1146/annurev-publhealth-031816-044318. Acesso em: 18 abr. 2018.

MARTIN, Ingerith; MACDONALD, Skye. Weak coherence, no theory of mind or executive dysfunction? Solving the puzzle of pragmatic language disorders. Brain and Language, v. 85, n. 3, p. 451-466, 2003. Disponível em: https://doi.org/10.1016/S0093-934X(03)00070-1. Acesso em: 18 jul. 2018.

MENDONÇA, Victor. Os desafios e as conquistas de um autista na universidade. Papo de Mãe, 2016. Disponível em: http://www.papodemae.com.br/2016/12/13/autista-nauniversidade/. Acesso em: 16 jul. 2018.

\begin{tabular}{l|c|c|c|c|c|c|} 
(C) Rev. Educ. Perspec. & Viçosa, $M G$ & v.9 & n.3 & p.668-693 & set./dez. 2018 & eISSN 2178-8359 \\
\hline
\end{tabular}


MERCADANTE, Marcos Tomanik. 41 ${ }^{\text {a }}$ Reunião Extraordinária da CAS. Brasília, 2010. Disponível em: http://www.senado.leg.br/atividade/comissoes/sessao/disc/listaDisc. asp?s=000028/10. Acesso em: 17 jul. 2018.

MOUSINHO, Renata. Linguagem-corpo na Síndrome de Asperger. In: FERREIRA, Carlos Alberto de Mattos; THOMPSON, Rita; MOUSINHO, Renata. Psicomotricidade Clínica. 1 ed. São Paulo: Lovise, 2002. P. 119-126.

NORA, Daiane; KONS, Luiza; AMORIM, Miriam. Autismo no ensino superior. Cotidiano UFSC, 2016. Disponível em: https://cotidianoufsc.atavist.com/autismo-no-ensino-superior. Acesso em: 16 jul. 2018.

OLIVATI, Ana Gabriela; LEITE, Lúcia Pereira. Trajetória acadêmica de um pós-graduando com transtorno do espectro autista. Psicol. Estud. Maringá, v. 22, n. 4, p. 609-621, out./dez. 2017. Disponível em: http://periodicos.uem.br/ojs/index.php/PsicolEstud/article/view/37665. Acesso em: 16 jul. 2018.

OMS. Organização Mundial da Saúde. Classificação de Transtornos Mentais e de Comportamentos: Descrições Clínicas e Diretrizes Diagnósticas (CID 10). 10 ed. Porto Alegre: Artes Médicas, 1993.

ONU. Organização das Nações Unidas. Convenção sobre os Direitos das Pessoas com Deficiência: Doc. A/61/611. Nova Iorque: ONU, 13 de dezembro de 2006. 2006. Disponivel em: https://goo.gl/DYy3tZ. Acesso em: 17 jul. 2018.

ONU. Organização das Nações Unidas. UN calls for recognizing the rights of people with autism to make their own decisions. United Nations Organization, USA, p. 1-2, mar. 2017. Disponível em: https://goo.gl/Anf6AD. Acesso em: 17 jul. 2018.

ORRÚ, Sílvia Ester. Aprendizes com autismo: aprendizagem por eixos de interesse em espaços não excludentes. Rio de Janeiro: Vozes, 2016.

ORRÚ, Sílvia Ester. Síndrome de Asperger: aspectos científicos e educacionais. Revista Iberoamericana de Educación, v. 53, n. 7, p 1-14, 2010. Disponível em: https://rieoei.org/RIE/article/view/1698. Acesso em: 18 abr. 2018.

PASTORELLO, Lucila Maria. Síndrome de Asperger. In: FERNANDES, Fernanda Dreux Miranda; PASTORELLO, Lucila Maria; SCHEUER, Claudia Ines. Fonoaudiologia nos distúrbios psiquiátricos da infância. São Paulo: Lovise, 1996. P. 45-59.

RÉVIL, Sophie. Le Cerveau d'Hugo. France, 2012. Disponível em: https://www.youtube.com/watch?v=PKhS4W1G234. Acesso em: 17 jul. 2018.

RODRIGUES, Ida Janete; ASSUMPÇÃO JR, Francisco Batista. Habilidades visoperceptuais e motoras na síndrome de Asperger. Temas psicol. Ribeirão Preto, v. 19, n. 2, p.

\begin{tabular}{l|l|l|l|l|l|l|} 
(C) Rev. Educ. Perspec. & Viçosa, $M G$ & v.9 & n.3 & p.668-693 & set./dez. 2018 & eISSN 2178-8359 \\
\hline
\end{tabular}


361-377, dez. 2011. Disponível em: http://pepsic.bvsalud.org/scielo.php?script= sci_arttext\&pid=S1413-389X2011000200002\&lng=pt\&nrm=iso. Acesso em: 18 jul. 2018.

SACKS, Oliver. Um Antropólogo em Marte. São Paulo: Companhia das letras, 1995.

SCHWARTZMAN, José Salomão. Síndrome de Asperger. Temas em Desenvolvimento. p. 19-21, 1992.

SECUNHO, Celiane Ferreira. Características psicológicas dos portadores da Síndrome de Asperger. In: CAMARGOS JR, Walter (Org.). Transtornos Invasivos do Desenvolvimento: 3o Milênio. 2 ed. Brasília: 2005. p. 88-93.

SOARES, Adriana Benevides; MOURA; Isabel Cristina Silva. Características da compreensão textual por alunos portadores da Síndrome de Asperger: um estudo exploratório. Mudanças - Psicologia da Saúde, v. 17, n. 1, p. 27-32, jan./jun. 2009.

Disponível em: https://www.metodista.br/revistas/revistas-ims/index.php/MUD/ article/view/1933. Acesso em: 16 jul. 2018.

SOUZA, Maria Antônia de. Movimentos sociais e sociedade civil. Curitiba: IESDE Brasil S.A., 2008.

\section{NOTAS}

\footnotetext{
' Diagnostic and Statistical Manual of Mental Disorders (DSM) ou Manual Diagnóstico e Estatístico de Transtornos Mentais.

ii Significa a ocorrência de mais de um problema ao mesmo tempo, além do quadro sintomático próprio do Transtorno do Espectro Autista, também a distração, hiperatividade, hiperlexia, discalculia dentre outros. A existência de comorbidade com o Transtorno do Espectro Autista é muito comum na maioria dos casos.
}

\section{Sobre a Autora}

1 Silvia Ester Orrú - Doutora em Educação. Docente da Universidade de Brasília e colaboradora na Universidade Federal de Alfenas. Brasil. E-mail: seorru7@gmail.com ORCID: http://orcid.org/0000-0002-4672-0471 